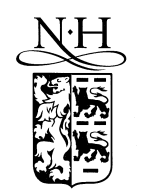

ELSEVIER
Applied Surface Science 153 (2000) 245-258 applied surface science

www.elsevier.nl/locate/apsusc

\title{
Lead deposition onto fractured vitreous carbon: influence of electrochemical pretreated electrode
}

\author{
E. Sosa, G. Carreño, C. Ponce-de-León, M.T. Oropeza, M. Morales, I. González, \\ N. Batina*
}

Universidad Autónoma Metropolitana-Iztapalapa, Departamento de Química, Apdo Postal 55-534, C.P. 09340 México, D.F., Mexico

Received 28 May 1999; accepted 21 August 1999

\begin{abstract}
We evaluated the electrochemical deposition of $\mathrm{Pb}(\mathrm{II})$ onto Fractured Vitreous Carbon (FVC) electrodes from solutions containing very low concentrations of lead in different electrolytes (sulfate or chloride). To examine how the FVC surface state influences the lead deposition efficiency, the electrodes were subjected to different electrochemical pretreatments prior to the actual deposition process. The FVC electrode was used as a representative model of the vitreous carbon (VC) bulk, avoiding the polishing procedure that could change the surface. Electrochemical pretreatment was carried out by cyclic voltammetry in electrolytes containing chloride or nitrate anions and in some cases, ferrocyanide. Before and after the electrochemical pretreatment, the electrode surface morphology was assessed using Atomic Force Microscopy (AFM) imaging. The quantity of lead deposited on the FVC electrode surface (lead deposition efficiency) in each experiment was estimated from the charge under the lead anodic, dissolution peak. Electrochemical pretreatment of electrodes in chloride or nitrate electrolytic baths consistently reduced the lead deposition efficiency. A detailed analysis, correlating lead deposition efficiencies to surface roughness and fractal dimension of the freshly prepared and electrochemically pretreated FVC electrodes, indicated that the decrease in efficiency corresponded to the change in electrode surface geometry. The greater efficiency of lead deposition observed in the chloride-containing electrolyte was due to the interaction between chloride and deposited lead rather than a chloride interaction with the FVC substrate. (C) 2000 Elsevier Science B.V. All rights reserved.
\end{abstract}

Keywords: Electrochemical pretreatment; Lead deposition; Vitreous carbon electrodes

\section{Introduction}

Electrolytic methods based on electrodeposition are convenient techniques used for removal of transition and heavy metals from effluents and environ-

\footnotetext{
* Corresponding author. Tel.: +52-5-8044670; fax: +52-58044666.

E-mail address: bani@xanum.uam.mx (N. Batina).
}

mental waters [1-6]. The optimization of these methods requires a fine definition of the metal deposition process; however, this is often a fundamental challenge [2,7-11].

The influence of anions in the deposition bath has been implicated as critical for efficient lead removal from electrolytic solutions $[2,12,13]$. Significant differences in the removal efficiency have been reported among electrolytes containing sulfate, nitrate or chloride anions. The presence of chloride anions 
in the electrolytic bath undoubtedly leads to the highest removal rate, with a several fold higher efficiency than the other electrolytes [2,13]. Removal carried out using sulfate containing electrolytes results in a significant decrease in efficiency. Neither the exact chemical influence of the different anions nor an explanation for the difference in removal efficiency has yet been described. To examine the lead removal phenomenon in sulfate and chloride solutions, we recently evaluated possible mechanisms, which could enhance (chloride) or inhibit (sulfate) lead electrodeposition onto non-polished electrodes (fractured vitreous carbon, FVC, and reticular vitreous carbon, RVC) [13]. In our preliminary study, we demonstrated that FVC could serve as a very good model surface for examining processes on RVC electrodes.

As a part of a large-scale evaluation of parameters, which could influence the metal deposition process on the carbon electrodes, we considered the notion of enhanced lead deposition onto vitreous carbon (VC) via the creation of additional active sites due to chloride co-adsorption at the electrode surface. The possible creation of additional active sites due to chloride adsorption onto FVC is based on the findings of Mostany et al. [12], who studied lead deposition onto the VC electrode using chloride electrolytic baths. This group reported that halides co-adsorb with lead at the VC surface at the deposition potentials thus providing new additional precursor active sites for metal nucleation. The authors suggested that this co-adsorption effect does not alter the kinetics of deposit growth, but it is expected to influence the deposit characteristics, including the deposit surface morphology.

We report our evaluation of the efficiency of the chloride-surface interaction during the lead deposition process onto FVC. Prior to the lead deposition process, which was carried out in the sulfate electrolytic bath, the FVC was electrochemically pretreated by performing cyclic voltammetry in a chloride-containing electrolyte. We expected that during the electrochemical pretreatment process the chloride anions would adsorb at the carbon electrode surface to create new active sites for lead nucleation. In order to resolve the specific influence of the chloride anion on the formation of the mentioned adlayer, we also used nitrate-containing electrolytes for the electrochemical pretreatment process. In both cases, FVC electrodes were pretreated with the above-mentioned anions in the presence and absence of $\left[\mathrm{Fe}(\mathrm{CN})_{6}\right]^{-3 /-4}$ as one of the standard electrochemical pretreatment substances [14]. In our knowledge, the present work is a pioneer study considering the FVC electrodes to analyze the substrate effect on the electrodeposition process. The amount of lead deposited at the electrode surface was evaluated by measuring the charge under the anodic dissolution lead peak (cyclic voltammetry). An ex situ Atomic Force Microscopy (AFM) analysis was performed to evaluate the electrode surface conditions, such as surface morphology characteristics before and after pretreatment, which can influence the rate and efficiency of the lead deposition process.

\section{Experimental}

\subsection{Electrochemical setup}

Electrochemical experiments involving lead deposition onto the FVC electrode and the electrochemical pretreatment processes were carried out by cyclic voltammetry with a potentiostat-galvanostat EG \& G PAR 283. A freshly prepared, manually fractured vitreous carbon (FVC) rod (0.3-cm-diameter rod purity $99.9 \%$ ) purchased from Alfa, AESAR, USA, was used as a working electrode. After manual fracturing, the electrode surface was evaluated visually and only electrodes with very similar surface areas were selected for further use. The sides of the FVC electrodes were isolated from the solutions using PTFE film. The surface area, for all electrodes, was approximately $0.071 \mathrm{~cm}^{2}$. Only one experiment was carried out with each fabricated electrode. In all experiments, a saturated $\mathrm{Hg} / \mathrm{Hg}_{2} \mathrm{SO}_{4}$ electrode (SSE) served as the reference electrode and a graphite rod (99.99\% Alfa, AESAR, USA) as a counter or auxiliary electrode.

\subsection{Electrochemical pretreatment}

Electrochemical pretreatment was carried out expecting to enhance, "activate", the number of active sites onto the FVC electrode for the lead deposition process, e.g., increase the efficiency. As part of this 
pretreatment, the FVC electrode was immersed into the electrolyte containing nitrate or chloride anion prior to lead deposition, and then scanned in the same range of electrode potentials as for the lead deposition process $(0.10$ to $-1.14 \mathrm{~V}$ vs. SSE). It is important to note that the potential range of scan potential is not sufficiently positive to increase of oxygen-carbon $(\mathrm{O}-\mathrm{C})$ ratio on the surface or to provoke the formation of graphite oxides [14]. It has been previously reported that the potential scan range used for the electrochemical pretreatment of the FVC surfaces provokes only surface structure modification of the VC electrodes surfaces. The FVC was cycled for 15 min with a constant velocity of $50 \mathrm{mV}$ $\mathrm{s}^{-1}$. Electrolytes were also tested with very low amounts of $\mathrm{K}_{4}\left[\mathrm{Fe}(\mathrm{CN})_{6}\right]$ salt, which is well characterized as chemical species for the electrochemical pretreatment of VCE [14]. Four different electrolytic solutions were utilized for these electrochemical treatment processes $(A-D)$ :

$$
\begin{aligned}
& \text { A. } 0.5 \mathrm{M} \mathrm{NaCl}(\mathrm{pH}=2), \\
& \text { B. } 0.5 \mathrm{M} \mathrm{NaCl}+1 \times 10^{-2} \mathrm{M} \mathrm{K}_{4}\left[\mathrm{Fe}(\mathrm{CN})_{6}\right] \\
& (\mathrm{pH}=7), \\
& \text { C. } 0.5 \mathrm{M} \mathrm{NaNO}_{3}(\mathrm{pH}=2), \\
& \text { D. } 0.5 \mathrm{M} \mathrm{NaNO}_{3}+1 \times 10^{-2} \mathrm{M} \mathrm{K}_{4}\left[\mathrm{Fe}(\mathrm{CN})_{6}\right] \\
& \quad(\mathrm{pH}=7) .
\end{aligned}
$$

Following the electrochemical pretreatment, electrodes were rinsed with ultra pure water and immediately transferred into a lead deposition bath. Identical experiments performed without rinsing established that this step did not change FVC characteristics.

\subsection{Lead deposition process}

Lead electrodeposition onto FVC and electrochemically pretreated FVC electrodes was carried out by the cyclic voltammetry technique, using 0.5 $\mathrm{M} \mathrm{Na} \mathrm{SO}_{4}$ and $0.5 \mathrm{M} \mathrm{NaCl}$ electrolytic solutions adjusted to $\mathrm{pH}=2$. After immersion of the FVC electrode into the electrolyte solution, the potential was scanned from the Open Circuit Potential (OCP) at $50 \mathrm{mV} \mathrm{s}^{-1}$ towards the negative limit $(-1.2 \mathrm{~V})$, and then in the reverse direction. The OCP varied with surface electrode conditions and with the electrolyte. Voltammograms for the lead deposition and dissolution processes were thus obtained. Lead concentration was kept at $7 \mathrm{ppm}\left(3.3 \times 10^{-5} \mathrm{M}\right)$ in the electrolytic baths. This low concentration was lower than the solubility value of lead in sulfate solutions. In different electrolytes, the corresponding salt of the lead species was always used.

For solution preparation, analytical grade $\mathrm{HCl}$, $\mathrm{HNO}_{3}, \mathrm{H}_{2} \mathrm{SO}_{4}, \mathrm{NaCl}, \mathrm{PbCl}_{2}, \mathrm{~Pb}\left(\mathrm{NO}_{3}\right)_{2}, \mathrm{NaNO}_{3}$, $\mathrm{PbSO}_{4}, \mathrm{Na}_{2} \mathrm{SO}_{4}$ were purchased from Merck and prepared using ultra pure, Milli- $\mathrm{Q}^{\mathrm{TM}}$ water.

\subsection{AFM measurements}

AFM, Nanoscope III, (Digital Instruments, USA, DI) was used to visualize the freshly prepared and electrochemically pretreated FVC electrode surfaces. The samples for AFM visualization were prepared according to the procedure described above, using different electrolytes. AFM imaging was performed ex situ, under laboratory conditions, by operating in contact mode with standard geometry silicon nitride probes from DI. Images were collected at the slow scan rate of $1 \mathrm{~Hz}$. Before AFM imaging, samples were rinsed with ultra pure water. Rinsed and nonrinsed samples showed the same patterns. Morphological characteristics of the untreated and electrochemically pretreated FVC electrode surfaces were quantitatively evaluated using the Nanoscope III software package for image analysis. To satisfy the statistical nature of the quantitative analysis, measurement images for each were collected from a number of different parts of the sample. No destruction of the sample was noticed during imaging. All images in this paper are presented in the so called "height mode", where higher parts of the surface appear brighter in the image. All images are plotted in a "top-view" presentation mode, with the same scale in the $x-y$ and $z$ direction $(x-y$ is equal to 2 $\mu \mathrm{m}$, and $z$ shows a range from 0 to $120 \mathrm{~nm}$ ).

\section{Results and discussion}

\subsection{Electrochemical pretreatment}

The FVC surface was modified by electrochemical pretreatment, scanning the electrode potential in the range from 0.1 to $-1.14 \mathrm{~V}$ vs. SSE. The surface modification was carried out by the cyclic voltammetry technique in several different electrolytes. The 
electrochemistry of the VC electrode in the used media is well known and has been reported previously [14]. In order to avoid perturbations [14], by the polishing procedure, the electrochemical pretreatments were performed on an immediately freshly air fractured surface. Although, each electrochemical pretreatment consisted of many cycles obtained during the 15-min scanning, only the first scan is presented here, since there was no difference between the first and last scan. Fig. 1a shows a typical voltammogram for FVC obtained in $0.5 \mathrm{M} \mathrm{NaCl}$ solution (adjusted to $\mathrm{pH} 2$ ). The electrochemical pretreatment started at $-0.450 \mathrm{~V}$ and stopped after $15 \mathrm{~min}$ at the positive potential limit, when chloride anions are adsorbed at the electrode surface. As expected, due to the absence of an electrode process, this voltammogram was almost featureless. The sharp decline in the current at the far negative potentials is related to hydrogen evolution.

In the presence of $1 \times 10^{-2} \mathrm{M} \mathrm{K}_{4}\left[\mathrm{Fe}(\mathrm{CN})_{6}\right]$, the voltammogram possessed two peaks characteristic for the quasi-reversible redox process of $\left[\mathrm{Fe}(\mathrm{CN})_{6}\right]^{-3 /-4}$ (Fig. 1b) [14-16]. The magnitude and position of the reduction and oxidation peaks did not change during the potential scanning, indicating that no Prussian blue film was formed on the electrode surface [17]. Formation of a precipitate adlayer (film) on the electrode surface, from electrolyte containing $\left[\mathrm{Fe}(\mathrm{CN})_{6}\right]^{-3 /-4}$ salts, could significantly change the electrode surface properties. However, at our $\mathrm{K}_{4}\left[\mathrm{Fe}(\mathrm{CN})_{6}\right]$ solution of $\mathrm{pH}=7$, the conditions are unfavorable for the formation of the Prussian blue film on the electrode surface. Because of the neutral $\mathrm{pH}$, hydrogen evolution took place at more negative potentials than in more acidic electrolytes $(\mathrm{pH}=2)$.

Fig. 1c shows the electrochemical pretreatment scan in a $0.5 \mathrm{M} \mathrm{NaNO}_{3}$ solution at $\mathrm{pH}=2$. It is almost identical to that observed for the chloridecontaining electrolyte, with the exception of a high capacitive current. The oxidation and reduction peaks of the $\left[\mathrm{Fe}(\mathrm{CN})_{6}\right]^{-3 /-4}$ redox system, obtained for the $0.5 \mathrm{M} \mathrm{NaNO}_{3}+1 \times 10^{-2} \mathrm{M} \mathrm{K}_{4}\left[\mathrm{Fe}(\mathrm{CN})_{6}\right](\mathrm{pH}$ $=7$ ) solution, show a higher peak current (Fig. 1d) than the peak current in Fig. 1b. It is important to note that the positive limit chosen for the scan potential range in the electrochemical pretreatments, is low in comparison with those used in the classical

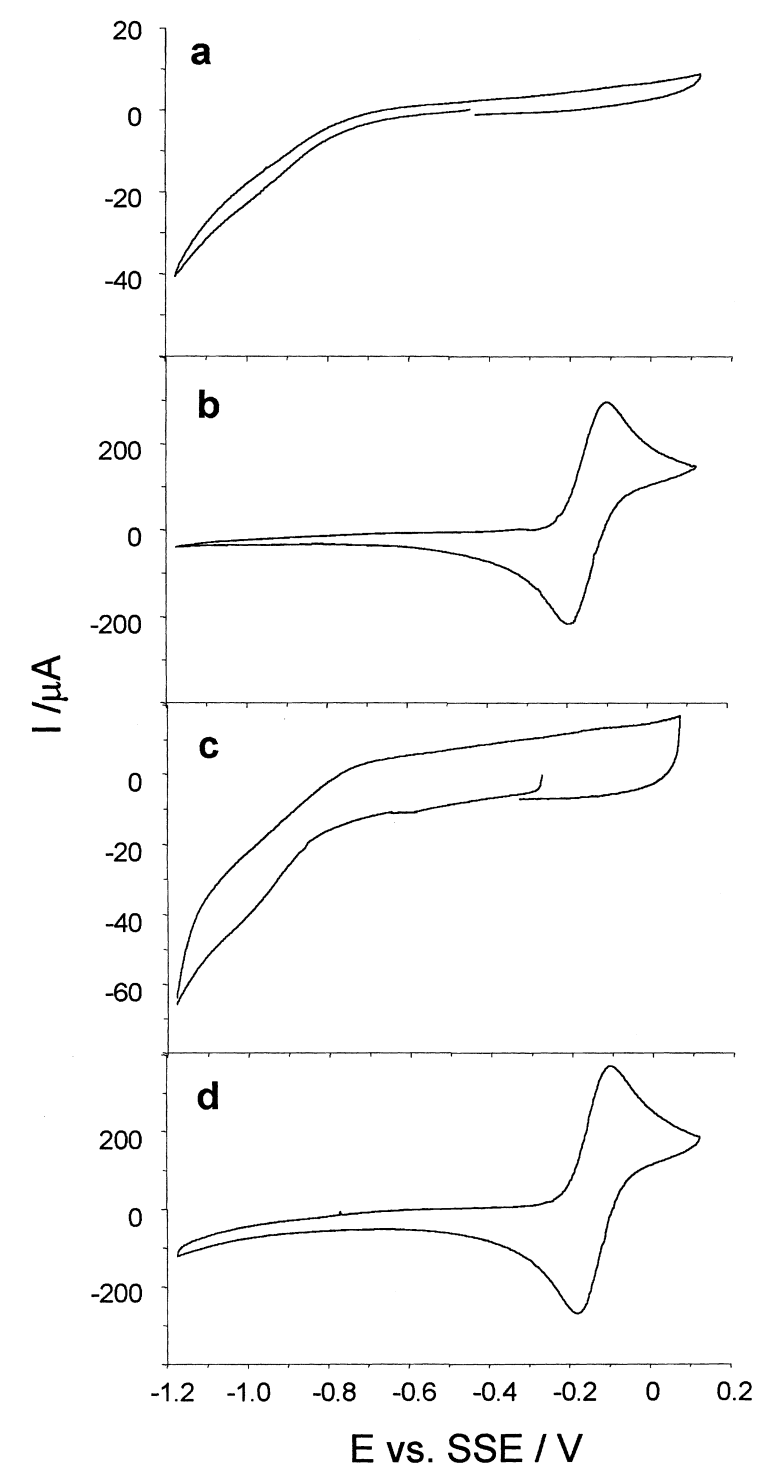

Fig. 1. Typical voltammograms obtained during the electrochemical pretreatment of FVC electrodes at a scan rate of $50 \mathrm{mV} / \mathrm{s}$. Pretreatment solutions were: (a) $0.5 \mathrm{M} \mathrm{NaCl}(\mathrm{pH}=2)$, (b) $0.5 \mathrm{M}$ $\mathrm{NaCl}+\mathrm{K}_{4}\left[\mathrm{Fe}(\mathrm{CN})_{6}\right](\mathrm{pH}=7)$, (c) $0.5 \mathrm{M} \mathrm{NaNO}_{3}(\mathrm{pH}=2)$ and (d) $0.5 \mathrm{M} \mathrm{NaNO}_{3}+10^{-2} \mathrm{M} \mathrm{K}_{4}\left[\mathrm{Fe}(\mathrm{CN})_{6}\right]$.

electrochemical pretreatments (1.8 to $1.5 \mathrm{~V}$ vs. SSE) [14]. In this way, we avoid the increase of the O-C ratio on the surface and the graphite oxide formation.

\subsection{Lead deposition onto FVC}

Lead electrodeposition onto FVC was carried out by cyclic voltammetry from $0.5 \mathrm{M} \mathrm{Na}_{2} \mathrm{SO}_{4}$ or $0.5 \mathrm{M}$ 
$\mathrm{NaCl}$ electrolytic solutions $(\mathrm{pH}=2)$ with $\mathrm{Pb}(\mathrm{II})$ at 7 ppm $\left(3.3 \times 10^{-5} \mathrm{M}\right)$. Figs. 2 and 3 show a set of typical voltammograms obtained in the electrolytic bath containing $\mathrm{Na}_{2} \mathrm{SO}_{4}$ for $\mathrm{FVC}$ after different electrochemical pretreatment processes. The three voltammograms in Fig. 4 are for lead deposition from $\mathrm{NaCl}$ electrolyte solution. The discontinuities in

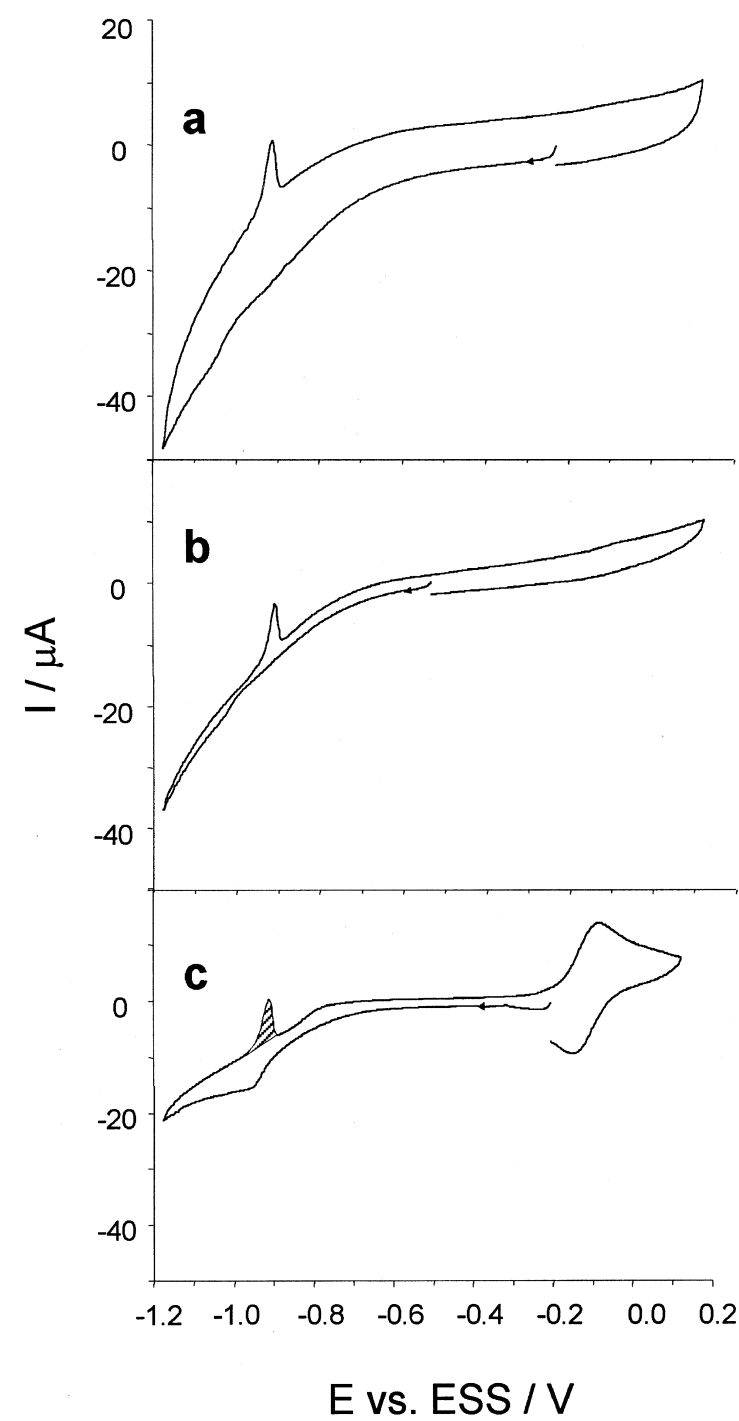

Fig. 2. Typical voltammograms obtained during lead deposition onto different electrochemical pretreated FVC electrodes at a scan rate of $50 \mathrm{mV} / \mathrm{s}$. Electrodeposition solution contained $0.5 \mathrm{M}$ $\mathrm{NaSO}_{4}$ and 7 ppm $\mathrm{Pb}(\mathrm{II})$. FVC electrodes used were: (a) freshly prepared surface, pretreated in: (b) $0.5 \mathrm{M} \mathrm{NaCl}(\mathrm{pH}=2)$, (c) 0.5 $\mathrm{M} \mathrm{NaCl}+\mathrm{K}_{4}\left[\mathrm{Fe}(\mathrm{CN})_{6}\right](\mathrm{pH}=7)$.

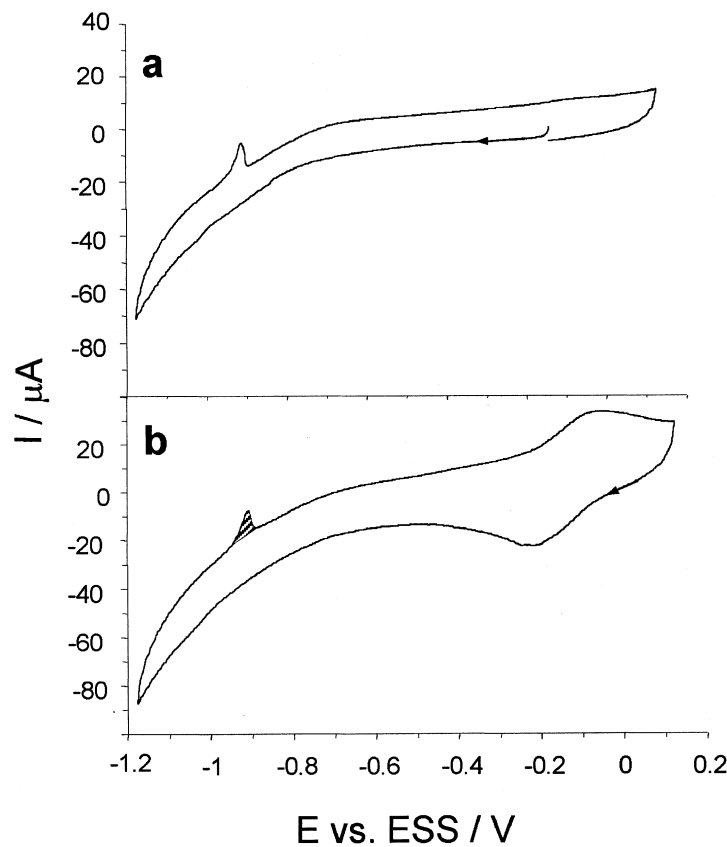

Fig. 3. Typical voltammograms obtained during lead deposition onto different electrochemically pretreated FVC electrodes at a scan rate of $50 \mathrm{mV} / \mathrm{s}$. Electrodeposition solution contained $0.5 \mathrm{M}$ $\mathrm{Na}_{2} \mathrm{SO}_{4}$ and $7 \mathrm{ppm} \mathrm{Pb}(\mathrm{II})$. FVC electrodes used were pretreated in: (a) $0.5 \mathrm{M} \mathrm{NaNO}_{3}(\mathrm{pH}=2)$ and (b) $0.5 \mathrm{M} \mathrm{NaNO}_{3}+10^{-2} \mathrm{M}$ $\mathrm{K}_{4}\left[\mathrm{Fe}(\mathrm{CN})_{6}\right]$.

voltammograms of Figs. 3 and 4 are principally due to the different OCP, before and after the potential scan.

The presence of a reversible process appears in the voltammogram for lead deposition onto FVC pretreated with ferrocyanide (Figs. 2c, 3b and 4b). This reversible couple appears in a similar potential for the species $\left[\mathrm{Fe}(\mathrm{CN})_{6}\right]^{-3 /-4}$. Considering that lead deposition electrolyte solutions are free from ferricyanide, the reversible couple observed in Figs. $2 \mathrm{c}, 3 \mathrm{~b}$ and $4 \mathrm{~b}$ indicates that the $\left[\mathrm{Fe}(\mathrm{CN})_{6}\right]^{-3 /-4}$ couple remains adsorbed on the FVC surface after the electrochemical pretreatment process even after lead deposition. The exact amount of the $\left[\mathrm{Fe}(\mathrm{CN})_{6}\right]^{-3 /-4}$ species is difficult to estimate since it depends on the anion position on the electrode surface area (real) and other unidentified factors. We estimated that the amount of charge under these peaks (on average between 43 to $45 \mu \mathrm{C}$ ) indicated a rather small amount of the species $\left[\mathrm{Fe}(\mathrm{CN})_{6}\right]^{-3 /-4}$, equivalent to between three and six monolayers. We 


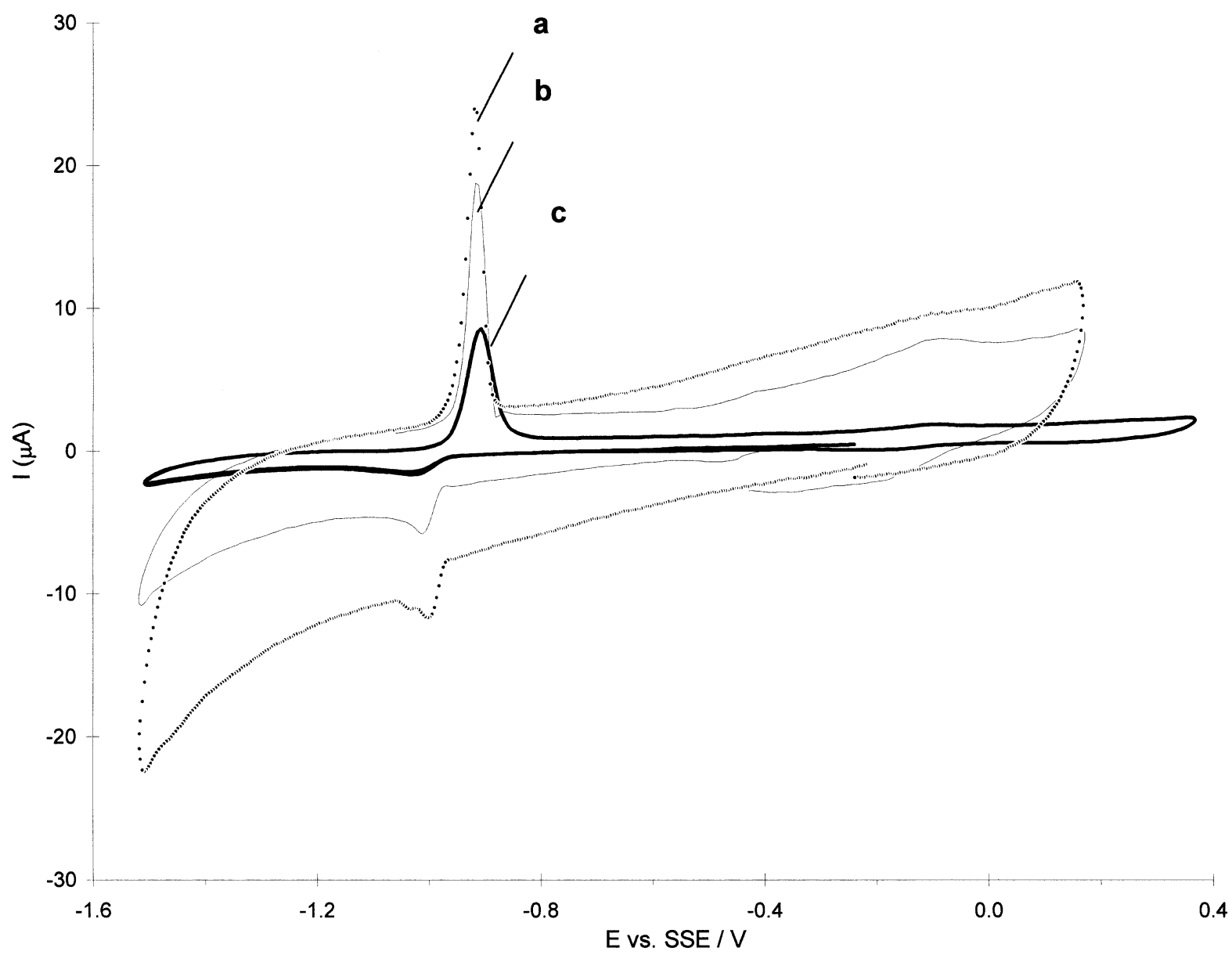

Fig. 4. Typical voltammograms obtained during lead deposition onto different electrochemically pretreated FVC electrodes at a scan rate of $50 \mathrm{mV} / \mathrm{s}$. The electrodeposition solution contained $0.5 \mathrm{M} \mathrm{NaCl}$ and $7 \mathrm{ppm} \mathrm{Pb}$ (II). The FVC electrodes used were: (a) freshly prepared surface and pretreated in: (b) $0.5 \mathrm{M} \mathrm{NaNO}_{3}+10^{-2} \mathrm{M} \mathrm{K}_{4}\left[\mathrm{Fe}(\mathrm{CN})_{6}\right](\mathrm{pH}=7)$ and (c) $0.5 \mathrm{M} \mathrm{NaCl}+10^{-2} \mathrm{M} \mathrm{K}{ }_{4}\left[\mathrm{Fe}(\mathrm{CN})_{6}\right](\mathrm{pH}=7)$.

do not have data concerning the distribution and exact origin of the $\left[\mathrm{Fe}(\mathrm{CN})_{6}\right]^{-3 /-4}$ on the $\mathrm{FVC}$ surface. However, taking into account that lead deposition is undisturbed by the presence of $\left[\mathrm{Fe}(\mathrm{CN})_{6}\right]^{-3 /-4}$, the electrode is unlikely to be covered by a thick $\left[\mathrm{Fe}(\mathrm{CN})_{6}\right]^{-3 /-4}$ film. This is presumably adsorbed material, which could easily be removed during the deposition process or is located on the surface such that it does not interfere significantly with the lead deposition process. In considering these possibilities, it is important to recall that our electrolytic bath contains only $7 \mathrm{ppm}$ of lead. Further work to determine the nature of the electrochemical pretreatment process of FVC by different anion species is currently underway in our laboratory.

A common feature in all the voltammograms is the single, well-defined oxidation peak at $-0.910 \mathrm{~V}$ appearing during the reverse scans. The position and shape of this peak is independent of the electrochemical pretreatment process and the electrolyte used during the deposition of lead and can be related to lead dissolution from the FVC electrode. The current and charge under this peak show clear dependence on the electrode surface pretreatment and the type of electrolyte present. The lead deposition peak in the forward scan (at ca. $-1.0 \mathrm{~V}$ ) was difficult to determine and define due to the high background (capaci- 
tive) current and the low $\mathrm{Pb}$ (II) concentration resulting in a small faradic current. We used the abovementioned dissolution peak to estimate the lead deposition efficiency onto FVC.

The amount of lead deposited was directly related to the overpotential value during the reduction process, which changed slightly with the electrochemical pretreatment of the electrode and the electrolyte present. Table 1 shows the total charge estimated under this anodic peak. Unexpectedly, for all the electrolytes, the highest charge, and therefore the highest amount of lead deposited, was obtained for a freshly prepared, FVC electrode. Any electrochemical pretreatment, for both electrolytes, resulted in a decrease in the amount of lead deposited. This means that the electrochemical pretreatment process based on chloride and nitrate-containing solutions did not "activate" the FVC surface. Contrary, the pretreatment could be described as a "deactivation" or "inhibition'. Therefore, FVC toward the electrodeposition process cannot be enhanced solely by the co-adsorption of chloride anions at the top layer surface, under the conditions of our study. The charge (efficiency), however, increased significantly when lead deposition was carried out from the chloridecontaining electrolyte as opposed to sulfate electrolyte. Chloride thus plays an important "activation" role during the lead deposition process, however, this enhancement requires the simultaneous presence of chloride anions and lead in the deposition bath. The higher efficiency of lead deposition in the chloride-containing electrolyte was thereby due to a chloride interaction with the deposited lead, rather than a chloride-FVC substrate interaction. This assumption will be verified by in-situ SPM techniques, directly during the electrodeposition process, work in progress.

\subsection{Characterization of electrode surface morphol- ogy by $A F M$}

FVC deactivation or inhibition could be due to changes in the electrode surface morphology produced during the electrochemical pretreatment. The fresh FVC electrode and the electrochemically pretreated FVC electrode surface morphologies were evaluated using ex situ AFM. As established previously, the kinetics and efficiency of the metal deposition process are frequently related to electrode surface morphology. We therefore considered the influence of total (specific) electrode surface vs. geometric (nominal) surface, or number of edge plains /steps, on the electrode surface and its influence on the population of the deposition active sites $[15,18-20]$. Although this relationship is not always simple and straightforward [21], we employed AFM characterization to reveal details of changes in the surface morphology, to determine chloride co-adsorption and its influence on the lead deposition process. Fig. 5 shows a set of typical AFM images obtained for the FVC electrode before and after different electrochemical pretreatment procedures.

Prior to imaging, samples were rinsed with ultra pure water. The freshly prepared FVC surface (Fig. 5a) possessed characteristic morphology with small rectangular or elliptical types of protrusions (nodular structure). This texture was very similar to that observed by STM [16] and also by SEM reported by Pontikos and McCreery [22]. Following electrochemical pretreatment in $\mathrm{NaCl}$ (Fig. 5b), the electrode

Table 1

Influence of the electrochemical pretreatment on the amount of lead deposited estimated from lead dissolution peak. Electrodeposition solutions were different as shown. Data is from the voltammograms shown in Figs. 2-4

\begin{tabular}{lll}
\hline $\begin{array}{l}\text { Electrolyte composition used for the } \\
\text { electrochemical pretreatment of FVC }\end{array}$ & $Q_{\mathrm{A}}\left(0.5 \mathrm{M} \mathrm{Na}_{2} \mathrm{SO}_{4}\right), \mu \mathrm{C}$ & $Q_{\mathrm{A}}(0.5 \mathrm{M} \mathrm{NaCl}), \mu \mathrm{C}$ \\
\hline Freshly prepared & $4.8 \pm 0.1$ & $14.0 \pm 0.1$ \\
$0.5 \mathrm{M} \mathrm{NaCl}$ & $3.2 \pm 0.1$ & - \\
$0.5 \mathrm{M} \mathrm{NaCl}+10^{-2} \mathrm{M} \mathrm{K}_{4} \mathrm{Fe}\left[(\mathrm{CN})_{6}\right]$ & $4.1 \pm 0.1$ & $9.6 \pm 0.1$ \\
$0.5 \mathrm{M} \mathrm{NaNO}_{3}$ & $4.4 \pm 0.1$ & - \\
$0.5 \mathrm{M} \mathrm{KNO}_{3}+10^{-2} \mathrm{M} \mathrm{K}_{4} \mathrm{Fe}\left[(\mathrm{CN})_{6}\right]$ & $3.9 \pm 0.1$ & $11.0 \pm 0.1$ \\
\hline
\end{tabular}



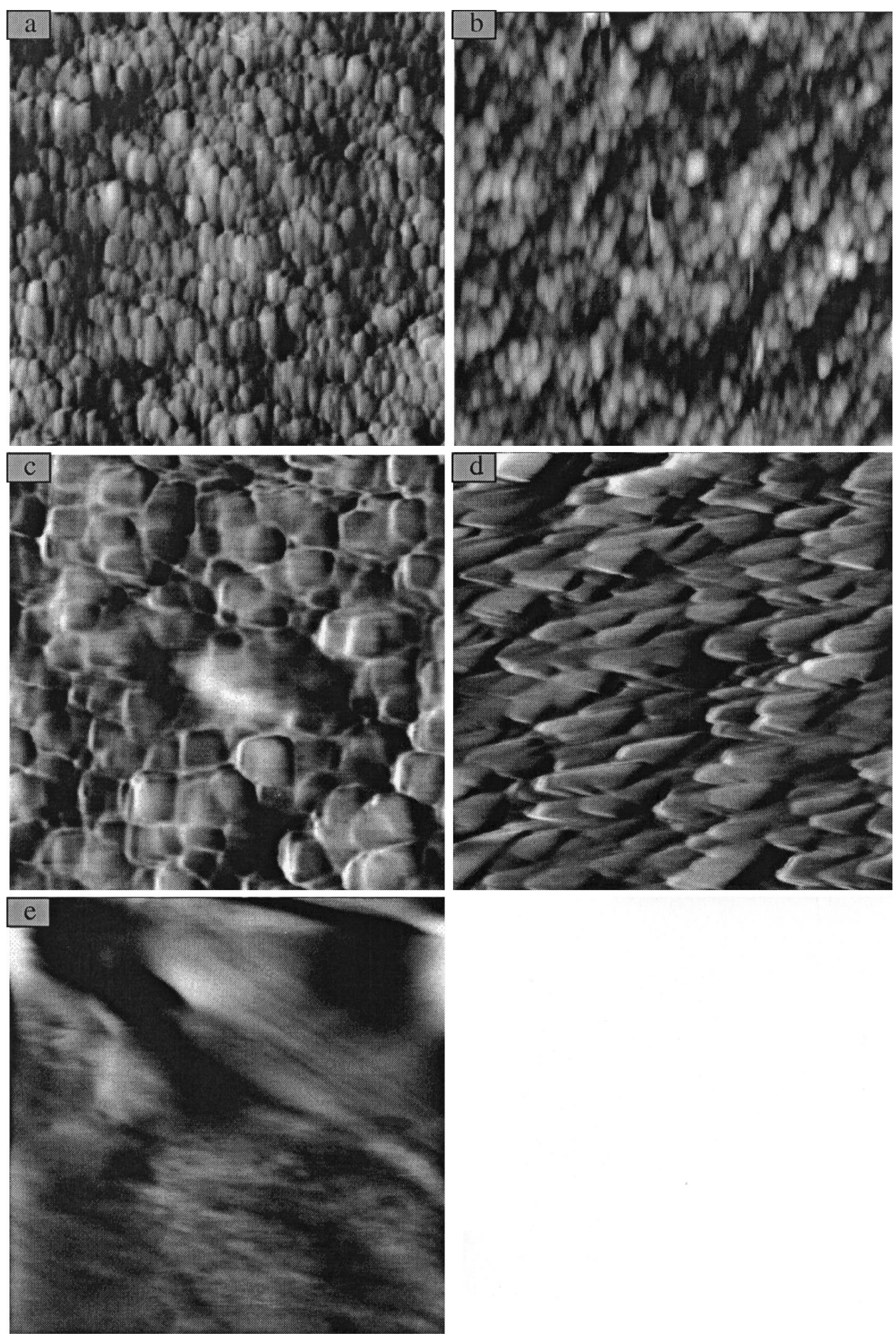

Fig. 5. AFM images of the FVC electrode surfaces $(2 \mu \mathrm{m} \times 2 \mu \mathrm{m})$ after electrochemical pretreatment process. (a) Freshly prepared surface with pretreatment solutions: (b) $0.5 \mathrm{M} \mathrm{NaCl}(\mathrm{pH}=2)$, (c) $0.5 \mathrm{M} \mathrm{NaCl}+\mathrm{K}_{4}\left[\mathrm{Fe}(\mathrm{CN})_{6}\right](\mathrm{pH}=7)$, (d) $0.5 \mathrm{M} \mathrm{NaNO}_{3}(\mathrm{pH}=2)$ and (e) $0.5 \mathrm{M}$ $\mathrm{NaNO}_{3}+10^{-2} \mathrm{M} \mathrm{K}_{4}\left[\mathrm{Fe}(\mathrm{CN})_{6}\right]$. 
surface changed very little from its original morphology. A nodular type of surface texture with approximately the same sized surface features can easily be recognized in the high-resolution images. However, the electrode surface appears to have a higher corru- gation. All images were plotted with the same scale in the $x, y$ and $z$ directions. Quite significant changes in the FVC surface morphology can be seen after electrochemical pretreatment in $0.5 \mathrm{M} \mathrm{NaCl}+1 \times$ $10^{-2} \mathrm{M} \mathrm{K}_{4}\left[\mathrm{Fe}(\mathrm{CN})_{6}\right](\mathrm{pH}=7)$ electrolyte. The main

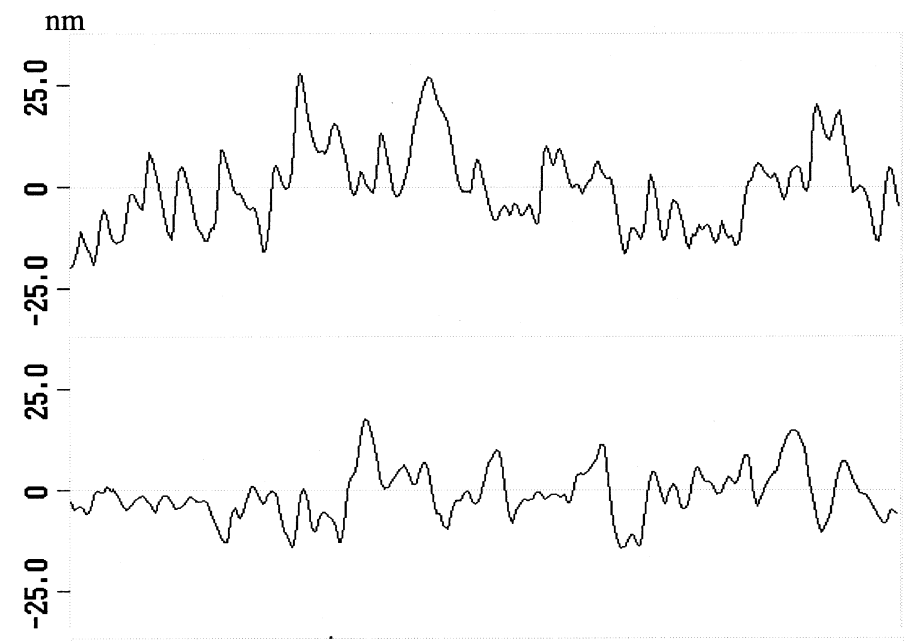

觜

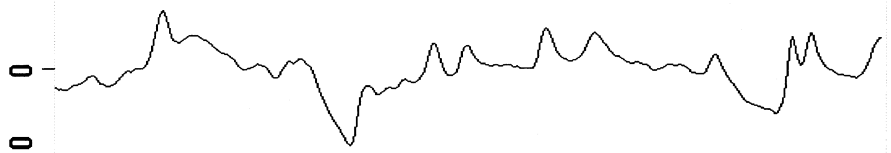

กั่

觜-

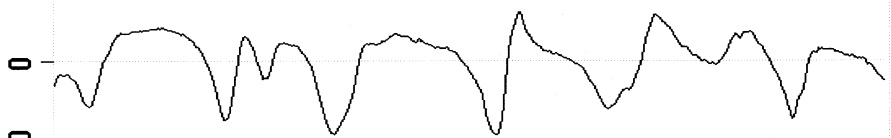

穴-

通

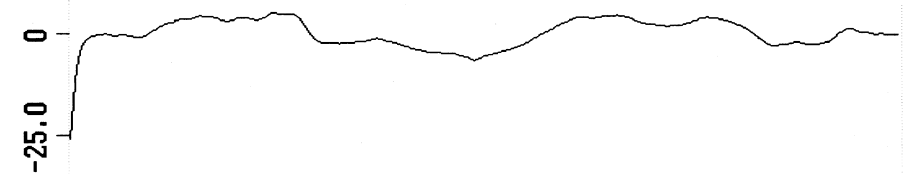

ó

1.00

2. 00

Fig. 6. Surface morphology illustrated by a set of cross-sections recorded on corresponding images (Fig. 5) of the FVC electrodes after electrochemical pretreatment. (a) Freshly prepared surface pretreated in: (b) $0.5 \mathrm{M} \mathrm{NaCl}\left(\mathrm{pH}=2\right.$ ), (c) $0.5 \mathrm{M} \mathrm{NaCl}+\mathrm{K}_{4}\left[\mathrm{Fe}(\mathrm{CN})_{6}\right]$ $(\mathrm{pH}=7),(\mathrm{d}) 0.5 \mathrm{M} \mathrm{NaNO}_{3}(\mathrm{pH}=2)$ and (e) $0.5 \mathrm{M} \mathrm{NaNO}_{3}+10^{-2} \mathrm{M} \mathrm{K}_{4}\left[\mathrm{Fe}(\mathrm{CN})_{6}\right]$. 
features become significantly larger, with a characteristic quadratic shape (Fig. 5c). However, it is unclear whether the morphology of the top electrode layer belongs to the FVC or to the adsorbed $\left[\mathrm{Fe}(\mathrm{CN})_{6}\right]^{-3 /-4}$ adlayer.

Activation in $0.5 \mathrm{M} \mathrm{NaNO}_{3}(\mathrm{pH}=2)$, produced rather large and triangular surface plates which were dispersed all over the electrode surface (Fig. 5d). FVC pretreated in $0.5 \mathrm{M} \mathrm{NaNO}_{3}+1 \times 10^{-2} \mathrm{M}$ $\mathrm{K}_{4}\left[\mathrm{Fe}(\mathrm{CN})_{6}\right](\mathrm{pH}=7)$ gave a very irregular and heterogeneous type of surface (Fig. 5e).

We performed a quantitative description of the electrode surface after each electrochemical pretreatment process to characterize the electrode surface and to interpret these findings in relation to the efficiency achieved for the particular lead deposition process. Before carrying out this process, we needed to determine which method to be used for surface morphology evaluation and which parameters would sufficiently and adequately provide an appropriate characterization.

We chose to evaluate the surface morphology parameters with the accompanying AFM software to estimate surface roughness and other morphological parameters on the basis of the whole set of collected points within the image analyzed. This was advantageous in the analysis of both the homogeneous and the FVC electrode surfaces. Fig. 6 shows a set of cross-section profiles taken from the upper part of the each image presented in Fig. 5.

To produce comparable images, these were plotted with the same $x$ - and $z$-scale. The profiles demonstrate the difference in height (corrugation in $z$-scale, related to the surface roughness) as well as lateral size among the surface features. Previous SPM studies [16,23-25] characterized the electrode surface via changes in the surface roughness (i.e., root-mean-square roughness, RMS $\left[R_{\mathrm{q}}\right]$ ) due to a variation in $z$-dimensions (height of the surface features). Fig. 6, however, illustrates that for a quantitative description, the surface morphology parameters, which are related to the height and lateral size, should also be taken into account. We thus selected the few, simple parameters of surface roughness, surface feature size and fractal dimension to characterize our system. Surface roughness, which changes in the $z$-direction due to a difference in the grain height, was estimated using RMS $\left[R_{\mathrm{q}}\right]$ function as described $[25,26]$. Table 2 shows that the highest $\operatorname{RMS}\left[R_{\mathrm{q}}\right]=8.974 \mathrm{~nm}$, was obtained for FVC without treatment. Interestingly, McDermott et al. [16] reported this same parameter as double our calculation. Our quantification may be due to higher resolution in the STM techniques used in this evaluation. Other surfaces with electrochemical pretreatment possessed smaller RMS $\left[R_{\mathrm{q}}\right]$, which meant that during the electrochemical pretreatment process, an actual smoothing out of the sample must have been occurring. According to this evaluation, the smoothest FVC surface was that pretreated in $0.5 \mathrm{M}$ $\mathrm{NaCl}+1 \times 10^{-2} \mathrm{M} \mathrm{K}_{4}\left[\mathrm{Fe}(\mathrm{CN})_{6}\right](\mathrm{pH}=7)$ solution. However, in comparison with the cross-section profiles in Fig. 6, the smoothest surface was the one pretreated in $0.5 \mathrm{M} \mathrm{NaNO} \mathrm{Na}_{3}+1 \times 10^{-2} \mathrm{M}$ $\mathrm{K}_{4}\left[\mathrm{Fe}(\mathrm{CN})_{6}\right](\mathrm{pH}=7)$ solution. The difference observed could be related to the fact that the RMS $\left[R_{\mathrm{q}}\right]$ was calculated from all points in the AFM image, and that the cross-section profile represents only $1 / 512$ of the total profiles in a single image.

Changes in the lateral dimensions of the surface features (along the $x$ and $y$ axes) are represented by parameters such as shape, size and feature density.

Table 2

Surface analysis from AFM images obtained from FVC electrodes after electrochemical pretreatment performed in different chemical solutions

\begin{tabular}{lllll}
\hline $\begin{array}{l}\text { Electrolyte composition used for the } \\
\text { electrochemical pretreatment of FVC }\end{array}$ & $\begin{array}{l}\text { RMS }\left(R_{\mathrm{q}}\right), \\
\mathrm{nm}\end{array}$ & $\begin{array}{l}\text { Feature shape and size } \\
\left(\mathrm{nm}^{2}\right)\end{array}$ & $\begin{array}{l}\text { Feature } \\
\text { density }\end{array}$ & $\begin{array}{l}\text { Fractal } \\
\text { dimension }\end{array}$ \\
\hline Freshly prepared & 8.974 & Rectangular, 7800-9750 & $1.02-1.28 \times 10^{10}$ & 2.561 \\
$0.5 \mathrm{M} \mathrm{NaCl}$ & 8.663 & Rectangular, 2000-7000 & $1.3-5.40 \times 10^{10}$ & 2.510 \\
$0.5 \mathrm{M} \mathrm{NaCl}+10^{-2} \mathrm{M} \mathrm{K}_{4} \mathrm{Fe}\left[(\mathrm{CN})_{6}\right]$ & 6.672 & Square, 22,500-32,400 & $3.09-4.44 \times 10^{9}$ & 2.413 \\
$0.5 \mathrm{M} \mathrm{Na} \mathrm{NO}_{3}$ & 8.128 & Triangular, 36,000-42,000 & $2.38-2.90 \times 10^{9}$ & 2.360 \\
$0.5 \mathrm{M} \mathrm{KNO}_{3}+10^{-2} \mathrm{M} \mathrm{K}_{4} \mathrm{Fe}\left[(\mathrm{CN})_{6}\right]$ & 7.380 & - & - & 2.280 \\
\hline
\end{tabular}


To complete this analysis, several features with dominant shapes and sizes were identified and their surface area was calculated. The main purpose of the analysis was to relate the feature density with active site density for the deposition process. We estimated that the surface with the greatest number of smallest features was most likely to have the largest number of plane edges and active sites. Our results showed that the feature density (and possibly the number of active sites for the lead deposition process) decreased due to the electrochemical pretreatment process (Table 2). This is the same trend at that observed for electrode roughness.

Since surfaces with larger numbers of grain edges could have more active sites and more specific area for the electrode reaction than a simple-flat surface, we also carried out fractal analysis on our electrode surface images to estimate the geometric complexity of the electrode surface. Fractal analysis, though complex and infrequently applied, provides a mathematical summary of the geometric complexity of the surface analyzed. Our evaluation employed an AFM software package. Fractal dimension provides an objective means for comparing two or many different fractals [27-29]. The fractal dimension of a three-dimensional surface, as is the case of our AFM images, besides having the characteristic feature in lateral $(x-y)$ axes, also depends on the surface roughness. Therefore, the fractal dimension represents the most complex parameter handled in our surface morphology characterization. Comparing the fractal geometry of differently prepared electrodes, we were able to see which surface was more complex in terms of the geometry of the top electrode features, and consequently, which surface provided the most active sites for the lead deposition process. Of course this is only true when the chemical composition of the surface layer remains constant during the electrochemical pretreatment process. Fractal analysis has been used in the characterization of metal electrodeposited surface morphology [30-33], yet no one has studied the bare electrode surface (substrate) or attempted to predict the efficiency of the deposition process based on the electrode surface fractal characteristics. For details of the fractal dimension evaluation, see the DI-manual on AFM [34]. The results of our evaluation are presented in Table 2. The highest fractal dimension and the highest

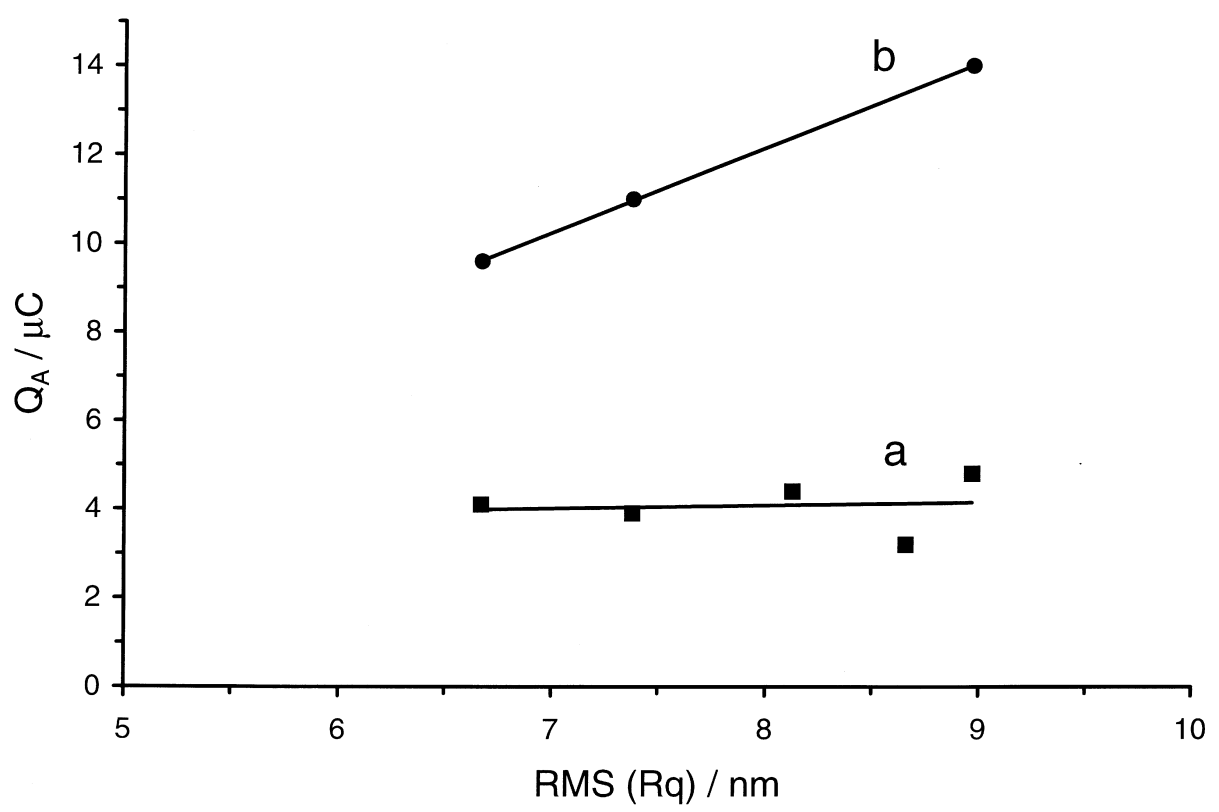

Fig. 7. Dependence of the lead deposition efficiency, expressed as a charge under the lead anodic peak from voltammograms in Figs. 2-4, $\left(Q_{\mathrm{A}}\right)$, on the electrode surface roughness (RMS $\left.\left[R_{\mathrm{q}}\right]\right)$. The FVC electrodes were pretreated under different chemical conditions. Lead deposition was carried out in solutions containing $7 \mathrm{ppm}$ of $\mathrm{Pb}$ (II) and: (a) $0.5 \mathrm{M} \mathrm{Na}_{2} \mathrm{SO}_{4}$ and (b) $0.5 \mathrm{M} \mathrm{NaCl}$. 
complexity were possessed by the FVC surface without electrochemical pretreatment (2.561). With electrochemical pretreatment in the chloride-containing electrolyte, the fractal dimension diminished. Note that in the case of a perfectly flat surface, such as a three-dimensional object, the fractal value is 2.000 . The lowest value among the samples tested was obtained for FVC treated in the nitrate solution.

A freshly prepared FVC, without electrochemical pretreatment, possessed the most complex surface morphology and would probably be the most efficient substrate in the lead deposition process. The electrochemical pretreatment process produced surface flattening, smoothing and the creation of larger and more uniform, top-layer surface features. The observed changes closely resembled the trends seen previously for surface roughness and feature density.

\subsection{Lead deposition efficiency vs. electrode surface morphology}

We correlated the lead deposition efficiency with the surface morphology characteristics of the FVC used. Fig. 7 shows the dependence of the amount of deposited lead (expressed via current of the anodicdissolution peak) on the electrochemically pretreated FVC electrode surface roughness (measured before the lead deposition process). For both deposition baths (sulfate and chloride), a linear relation was established. The amount of lead deposited increased as the electrode surface roughness increased, as expected when higher electrode surface areas were available for the deposition process. Regardless of the RMS values, the amount of lead deposited in the chloride-containing electrolytic bath was always greater than in the sulfate-containing bath. Considering the slopes of the lines in Fig. 7, alterations in the surface roughness apparently caused a more significant increase/decrease in the lead efficiency for deposition from the chloride electrolyte than from the sulfate. Fig. 8 shows the relationship between $Q_{\text {A }}$ (amount of lead deposit) and the value of the fractal dimension for FVC after different electrochemical pretreatment processes. Although, the linear relationship is not as good as in the case of RMS, it is certain that lead efficiency is also related to the

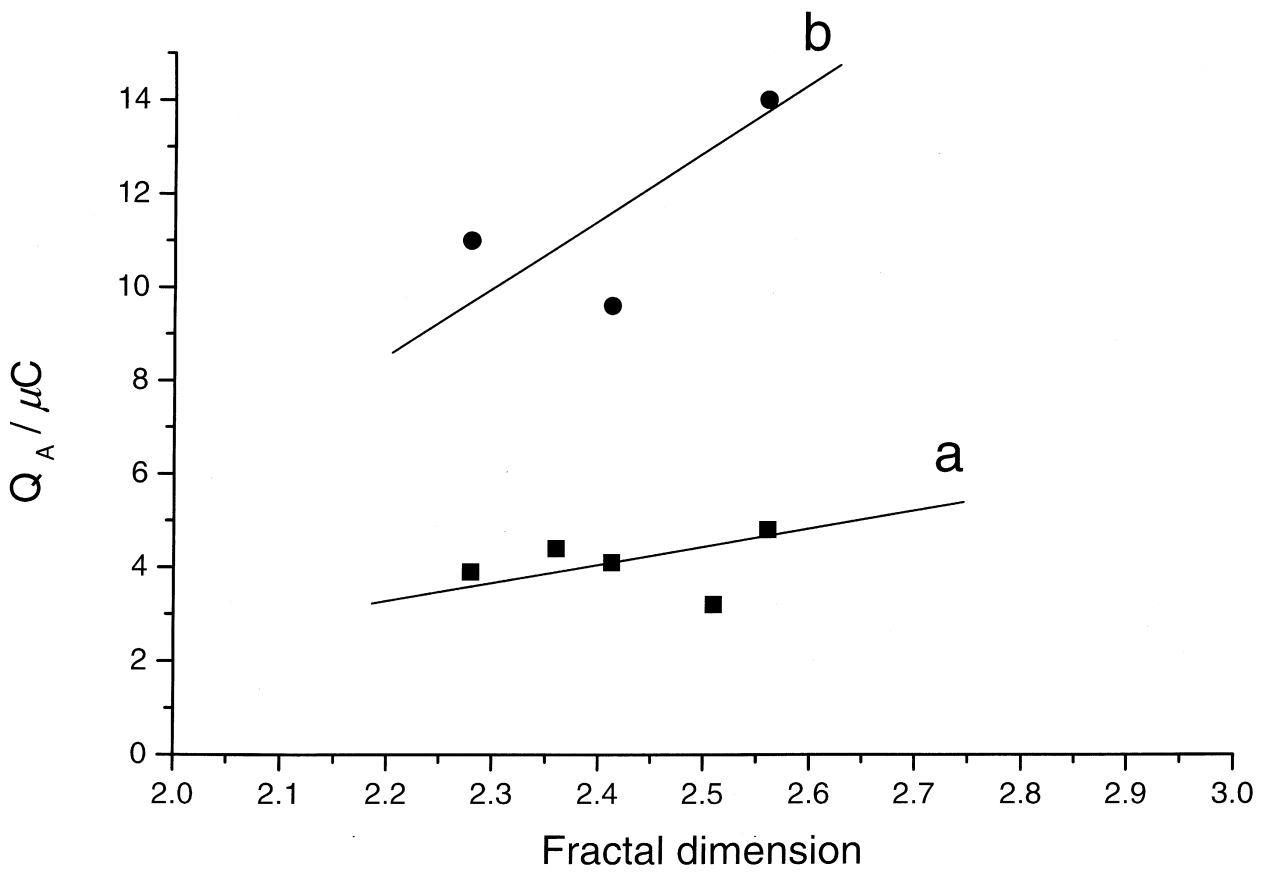

Fig. 8. Dependence of the lead deposition efficiency, expressed as a charge under the lead anodic peak from voltammograms in Figs. 2-4, $\left(Q_{\mathrm{A}}\right)$, on the electrode fractal dimension parameter. The FVC electrodes were pretreated under different chemical conditions. Lead deposition was carried out in solutions containing $7 \mathrm{ppm}$ of $\mathrm{Pb}$ (II) and: (a) $0.5 \mathrm{M} \mathrm{Na}_{2} \mathrm{SO}_{4}$ and (b) $0.5 \mathrm{M} \mathrm{NaCl}$. 
fractal dimension of the substrate surface. This is the same kind of relationship observed in the $Q_{\mathrm{A}} / \mathrm{RMS}$ graph and is expected, since fractal dimension is, among other factors, also a function of RMS. The same or very similar relationships between deposition efficiency and electrode morphology were observed when comparing the graphs in Figs. 7 and 8 . Therefore, electrode surface characterization, via the estimation of RMS or fractal dimension, was of similar importance.

The impact of electrode geometry on the lead deposition process is showed in these graphs. Changes in lead deposition efficiency were strictly related to alterations in electrode morphology (geometry effect). By extrapolating the lines obtained to limiting values of fractal dimension and RMS (interception with the $y$-axis), it is possible to estimate an efficiency of 2.2 times higher for the sulfate and 2.7 to 3.3 times higher for the chloride baths. The higher efficiency is attributable to surface roughening or an increase in the fractal dimension of the electrode surface. Certainly, this type of estimate is also valid in reverse for inhibition due to the surface smoothing effect (our data).

\section{Conclusions}

The electrolytic removal of $\mathrm{Pb}$ (II) by electrodeposition onto fractured vitreous carbon (FVC) electrodes from aqueous solutions containing chloride or sulfate electrolytes was evaluated. Based on previous reports that lead deposition efficiency could be increased by the co-adsorption of chloride species at the substrate surface, we subjected our FVC electrodes to different electrochemical pretreatments prior to the actual deposition process. Electrochemical pretreatment was carried out by cyclic voltammetry in electrolyte solutions containing chloride or sulfate anions. In some solutions, a $\left[\mathrm{Fe}(\mathrm{CN})_{6}\right]^{-3 /-4}$ couple was used as well. The electrochemical behavior of the pretreatment process appeared to be simple, and did not indicate a great modification of the electrode surface. The chosen voltammetric pretreatment avoids the increase of $\mathrm{O}-\mathrm{C}$ ratio and carbon oxide formation on the pretreated electrode. The electrode surface was characterized by AFM before and after electrochemical pretreatment. The image obtained indicated the changes in the electrode surface morphology were due to the electrochemical pretreatment process. In order to characterize the observed changes quantitatively, several parameters, such as surface roughness, fractal dimension and surface feature density were used. AFM images revealed that electrochemical pretreatment lead only to electrode surface smoothing. The freshly prepared, untreated FVC surface had the highest roughness and highest fractal dimension (surface complexity).

The quantity of lead deposit formed on the FVC electrode surface (lead deposition efficiency) in each experiment was estimated from the charge under the lead anodic (dissolution) peak. The results obtained showed that using the electrochemical pretreatment process based on the exposure to chloride or nitrate anions, with or without the presence of $\left[\mathrm{Fe}(\mathrm{CN})_{6}\right]^{-3 /-4}$, failed to "activate" the FVC electrode in terms of an increase in the lead deposition efficiency. On the contrary, following any of the electrochemical pretreatment processes, this efficiency always decreased.

A detailed analysis based on the correlation between the lead deposition efficiency with a surface roughness and fractal dimension of the freshly prepared and electrochemical pretreatment processed FVC electrodes showed that the observed decline in the efficiency corresponded to changes in the electrode surface geometry. The smoother surfaces with lower roughness and lower fractal dimension most probably also possessed lower numbers of steps/grain edges, which in the case of the metal deposition process could be valuable active sites. However, our data also clearly indicated a difference between the lead deposition efficiency carried out in chloride vs. sulfate electrolyte. The chloride electrolytic bath for lead deposition resulted in a several fold higher efficiency than the sulfate bath. The observed increase was related to the presence of chloride during the lead deposition process, and not to chloride accumulation on the electrode surface prior to the deposition process. The increase in the lead deposition efficiency was based on the "activation' mechanism involving a chloride-lead deposit interaction or, as we stated previously, the lead deposits smoothing effects.

The FVC is a good model for studying RVC electrochemical properties. For these reasons, we 
expect that the conclusions concerning the electrochemical pretreatment could be useful to improve the technological applications of the RVC in several electrolytic processes as metal removal from aqueous solutions, substrate for conductor polymers deposition and electroreduction of water. This work suggest that $\mathrm{Pb}$ (II) removal from the electrolytic baths containing sulfate could be improved if the electrodeposition process is performed in the presence of chloride ions. The appropriate concentration of sulfate-chloride in solution must yet be established for optimized lead removal from lead-containing waters.

\section{Acknowledgements}

This research project was financially supported by CONACYT (Projects No. 0913E-P, L0081-E9608 and 400200-5-4250PA). G. Carreño and E. Sosa acknowledge the scholarships received from CONACYT.

\section{References}

[1] D. Pletcher, F.C. Walsh, Industrial Electrochemistry, 2nd edn., Blackies Bishopbriggs, Glasgow, 1993.

[2] C. Ponce de León, D. Pletcher, Electrochim. Acta 41 (1996) 533.

[3] F.C. Walsh, Electrochemical Technology for a Cleaner Environment, in: J.D. Genders, N. Weinberg (Eds.), The Electrosynthesis, Lancaster, New Jersey, 1992, Chap. 5.

[4] G. Lacoste, DECHEMA Monogr. 123 (1990) 411.

[5] F.C. Walsh, A First Course in Electrochemical Engineering, The Electrochemical Consultancy, 1993.

[6] R.C. Widner, M.F.B. Souza, R. Bertazzoli, J. Appl. Electrochem. 28 (1998) 201.

[7] A.T. Kuhn (Ed.), Industrial Electrochemical Processes, Elsevier, Amsterdam, 1971

[8] J.O'M. Bockris (Ed.), Electrochemistry of Cleaner Environments, Plenum, New York, 1972

[9] R. Kammel, H.W. Lieber, Galvanotechn 68 (1977) 413.
[10] G. Kreysa, Metalloberflache 35 (1981) 211.

[11] M. Palomar-Pardave, M.T. Ramirez, I. González, A. Serruya, B.R. Scharifker, J. Electrochem. Soc. 143 (1996) 1551.

[12] J. Mostany, J. Parra, B. Scharifker, J. Appl. Electrochem. 16 (1986) 333

[13] G. Carreño, E. Sosa, I. González, C. Ponce de León, N. Batina, M.T. Oropeza, Electrochim. Acta 44 (1999) 2633.

[14] R.L. McCreery, in: A.J. Bard (Ed.), Electroanalytical Chemistry. A Series of Advances 17 Marcel Dekker, New York, 1991, p. 221.

[15] R.J. Rice, N.M. Pontikos, R.L. McCreery, J. Am. Chem. Soc. 112 (1990) 4617.

[16] M.T. McDermott, C.A. McDermott, R.L. McCreery, Anal. Chem. 65 (1993) 937.

[17] R. Yang, Z. Quian, J. Deng, J. Electrochem. Soc. 145 (1998) 2231.

[18] E.B. Budevski, in: B.E. Conway, J.O’M. Bockris, E. Yeager, S.U.H. Khan, R.E. White (Eds.), Comprehensive Treatise of Electrochemistry 7 Plenum, New York, 1987, Chap. 7.

[19] N. Batina, T. Will, D.M. Kolb, Faraday Discuss. 94 (1992) 93.

[20] M.H. Holzle, V. Zwing, D.M. Kolb, Electrochim. Acta 40 (1995) 1237.

[21] R. Rice, C. Allerd, R. McCreery, J. Electroanal. Chem. 263 (1989) 163

[22] N.M. Pontikos, R.L. McCreery, J. Electroanal. Chem. 324 (1992) 229

[23] R.J. Phillips, T.D. Golden, M.G. Shumsky, J.A. Switzer, J. Electrochem. Soc. 141 (1994) 2391.

[24] D. Aubach, Y. Cohen, J. Electrochem. Soc. 143 (1996) 3525.

[25] Y.G. Li, A. Lasia, J. Appl. Electrochem. 27 (1997) 643.

[26] K. Jowal, L. Xie, R. Hug, G.C. Farrington, J. Electrochem. Soc. 139 (1992) 2818.

[27] B.B. Mandelbrot, The Fractal Geometry of Nature, Freeman, San Francisco, 1977.

[28] J. Feder, Fractals, Plenum, New York, 1988.

[29] M.F. Barnsley, Fractals Everywhere, Academic Press Professional, Boston, 1993.

[30] R.M. Brady, R.C. Ball, Nature 309 (1984) 225.

[31] M.M. Gomez, L. Vazquez, R.C. Salvarezza, J.M. Vara, A.J. Arvia, J. Electroanal. Chem. 317 (1991) 125.

[32] P. Herrasti, P. Ocon, R.C. Salvarezza, J.M. Vara, L. Vazquez, A.J. Arvia, Electrochim. Acta 37 (1992) 2209.

[33] J.M. Gomez-Rodriguez, A.M. Baro, L. Vazquez, R.C. Salvarezza, J.M. Vara, A.J. Arvia, J. Phys. Chem. 96 (1992) 347.

[34] Digital Instruments, Nanoscope III, Manual. 